\title{
Indoor Crowd Density Monitoring System Based on WeChat Public Platform
}

\author{
Zhitao Wang ${ }^{\text {a) }}$, Lei Ding \\ School of Computer, Guangdong University of Technology, Guangdong 510006, China. \\ a) Zhitao Wang: 745763006@qq.com
}

\begin{abstract}
To reduce the cost of crowd density monitoring in indoor space, facilitate supervisors to monitor crowd density in indoor space at any time. The article uses the characteristics of indoor temperature and humidity changes with the number of changes and combines WeChat Public Platform and design this indoor crowd density monitoring system. In order to improve the accuracy of the system, in this article, the collected temperature and humidity data were filtered and preprocessed, and then the approximate relationship between temperature and humidity and population density was found by linear fitting method. Through the experimental test of this system, the system is reasonable in design, easy to use, and can accurately monitor the indoor population density.
\end{abstract}

Key words: Crowd density monitoring; Temperature and humidity data; WeChat public platform.

\section{INTRODUCTION}

The WeChat public platform is an information transmission platform developed by Tencent for WeChat users and provides users with a development interface for the public platform. The WeChat public platform has attracted the attention of many markets and companies since its launch [1]. With the huge number of users owned by WeChat, it has gradually and comprehensively deepened its production and life.

With the rapid development of social economy and urban construction, more and more people are pouring into cities. In order to protect the people's happy life, effective crowd density monitoring for crowded places has become an urgent problem to be solved [2]. The traditional cameras, infrared and other monitoring methods can meet the monitoring requirements, but the cost is relatively high, and it is not easy to monitor the indoor crowd density anytime anywhere. The article uses the characteristics of human body temperature and exhaled gas to have a great influence on the temperature and humidity of the indoor space [3], makes a reasonable analysis of the temperature and humidity data, and designs this indoor crowd density monitoring system in conjunction with the WeChat public platform. Through the WeChat public platform, the system greatly reduces the development cost, reduces the difficulty of equipment installation, facilitates promotion and use among users, and can obtain crowd density information through the WeChat public number at any time.

\section{OUR DESIGN}

As shown in Figure 1, the system is mainly composed of a temperature and humidity sensor module, a power supply module, a main control module, a Wi-Fi module, a cloud server, a WeChat server, and a mobile WeChat client. temperature and humidity sensor use DHT11, main control module use SMT32, Wi-Fi module use ESP8266, cloud server use aliyun. 


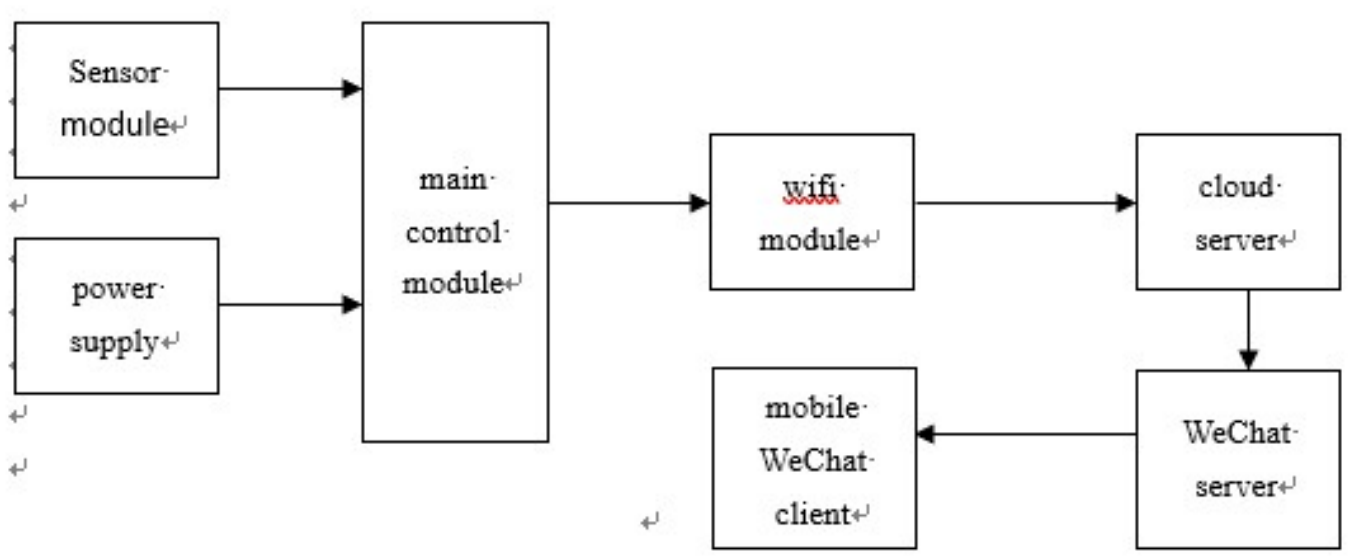

FIGURE 1. Structure of Whole System

\section{PRE-PROCESSING OF TEMPERATURE AND HUMIDITY DATA}

Pre-processing the collected temperature and humidity data in this section. Because the sensor is affected by the surrounding environment, the collected data will inevitably have a deviation from the real value [4], so the data needs to be preprocessed. We use the distribution map method [4] and the low-pass filter algorithm [5] to filter abnormal data. The basic process is as follows:

(1) Firstly, collect $\mathrm{n}$ data in succession, from small to large $\left(t 1, t 2, t 3 \ldots t_{n}\right)$, let $t_{m}$ be the median:

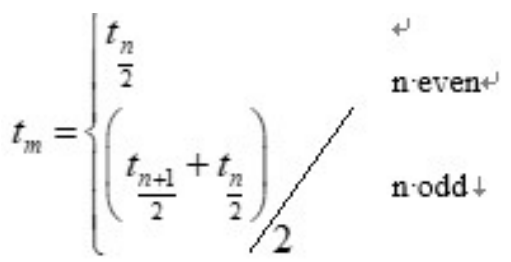

(2) Definition the median of $\left(t 1, t 2, t 3 \ldots t_{m}\right)$ is $t_{s}$, the median of $\left(t_{m+1} \cdots t_{n}\right)$ is $t_{x}$, followed by (1).

(3) The value of the definition of abnormal data is $d_{t}$ :

$$
d_{t}=d_{s}-d_{x}
$$

(4) Using a weighted mean filter algorithm to obtain the average of $n$ samples

$$
y(k-1)=\frac{1}{n} \sum_{i=1}^{n} C_{i} t(i)
$$

(5) If $|t(k)-y(k-1)| \geq d_{t}$, low-pass filter algorithm for this sampling, the final algorithm is as follows:

$$
y(k)=\left\{\begin{array}{lr}
t(k) & |t(k)-y(k-1)|>\beta d_{t} \\
\frac{T}{T+T_{f}} t(k)+\frac{T}{T+T_{f}} y(k-1) & |t(k)-y(k-1)| \leq \beta d_{t}
\end{array}\right.
$$

In the formula, $t_{k}$ is the original data collected this time, $\mathrm{y}(k)$ is the processed data, $\mathrm{T}$ is the sampling period, $T_{f}$ is the time length, and $\beta$ is the accuracy of the sensor. 


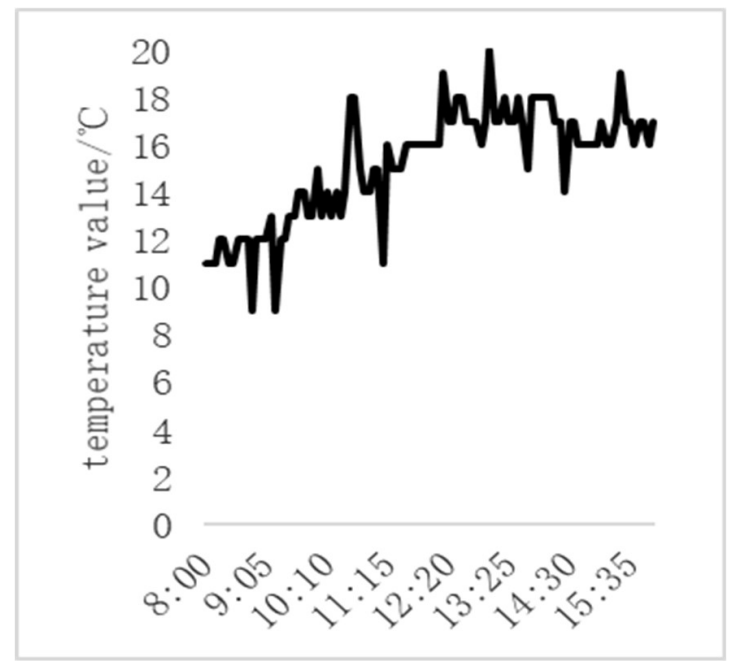

FIGURE 2. Pre-filter Temperature Data

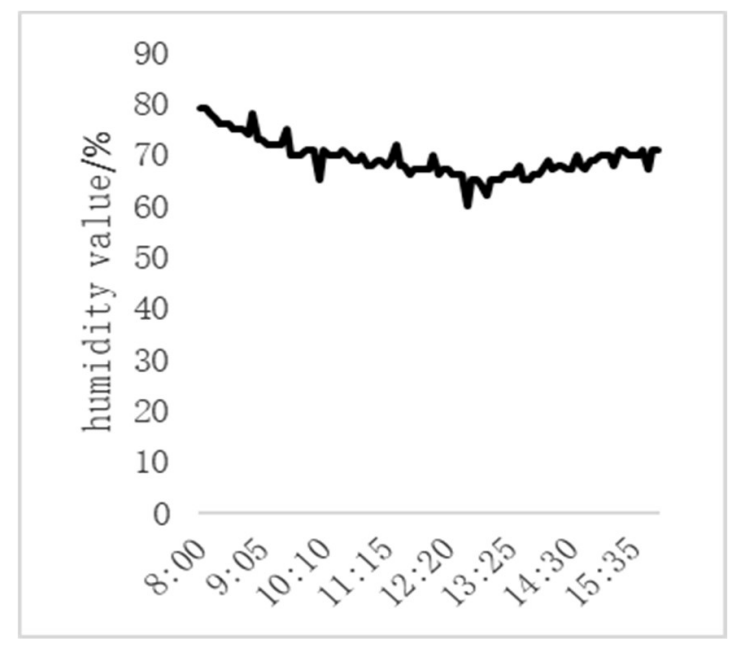

FIGURE 4. Pre-filter Humidity

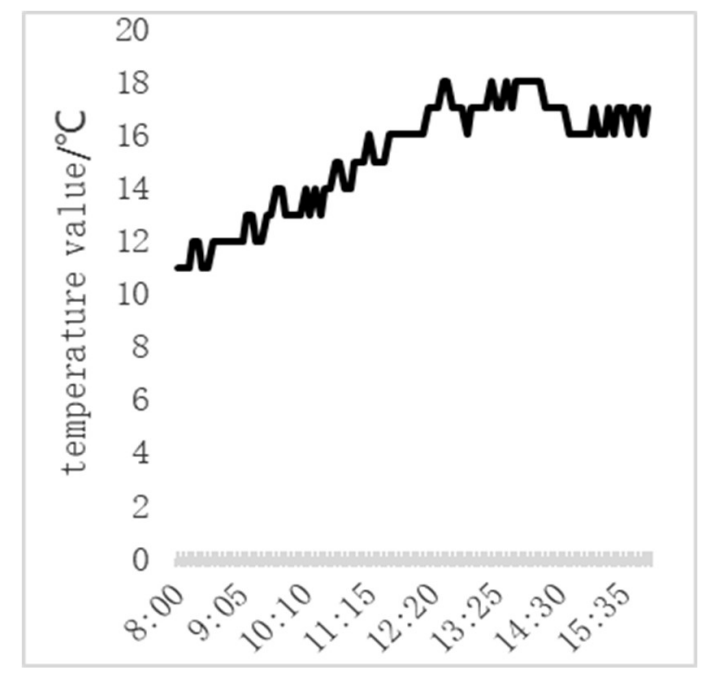

FIGURE 3. Filtered Temperature Data

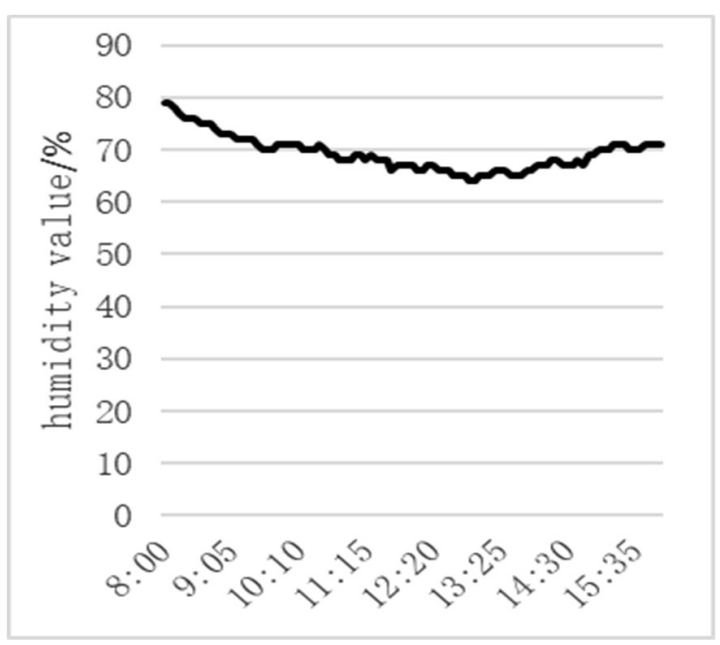

FIGURE 5. Data Filtered Humidity Data

\section{Temperature and Humidity Data Analysis}

This section analyzes the collected data and estimates the population density in a confined space based on the collected temperature and humidity data [3]. According to the general population density level classification standard [2], data collection is performed for different numbers of diurnal space and analyzed.

The temperature and humidity data are shown in TABLE 1.

TABLE 1. Temperature and Humidity data

\begin{tabular}{ccccccc}
\hline Persons & 0 & 4 & 8 & 14 & 20 \\
\hline Humidity $/ \% \mathrm{RH}$ & 68 & 69 & 70 & 74 & 79 \\
Temperature $/{ }^{\circ} \mathrm{C}$ & 17 & 17 & 18 & 19 & 21 \\
\hline
\end{tabular}

The temperature and humidity data are zeroed and the normalized data are shown in TABLE 2 
TABLE 2. Zero Data

\begin{tabular}{cccccc}
\hline Persons & 0 & 4 & 8 & 14 & 20 \\
\hline Zero Humidity $/ \%$ RH & 0 & 1 & 2 & 6 & 11 \\
Zero Temperature $/{ }^{\circ} \mathrm{C}$ & 0 & 0 & 1 & 2 & 4 \\
Normalized Humidity & 0 & 0.09 & 0.18 & 0.55 & 1 \\
Normalized Temperature & 0 & 0 & 0.25 & 0.5 & 1 \\
Model $(x)$ & 0 & 0.09 & 0.31 & 0.74 & 1.41 \\
\hline
\end{tabular}

The densities of the population in the diverticulum space are shown in TABLE 3.

TABLE 3. Level Markup

\begin{tabular}{cccccc}
\multicolumn{5}{c}{ TABLE 3. Level Markup } \\
\hline Density Level & Very Low & Low & Medium & High & Very High \\
\hline Servie Level & Free Flow & Constrain Flow & Dense Flow & Very Dense Flow & Block \\
Model Calibration & $\mathrm{x}<0.09$ & $0.09<\mathrm{x}<0.31$ & $0.31<\mathrm{x}<0.74$ & $0.74<\mathrm{x}<1.41$ & $\mathrm{x}>1.41$ \\
\hline
\end{tabular}

The results of the 3rd-order fitting of the vector modulus and the number of people are as follows:

$\mathrm{f}(\mathrm{x})=\mathrm{p} 1 * \mathrm{x}^{\wedge} 3+\mathrm{p} 2 * \mathrm{x}^{\wedge} 2+\mathrm{p} 3 * \mathrm{x}+\mathrm{p} 4$

Coefficients (with $95 \%$ confidence bounds):

$\mathrm{p} 1=9.784 \mathrm{e}-06(-0.0005749,0.0005945)$

$\mathrm{p} 2=0.002499(-0.01514,0.02014)$

$\mathrm{p} 3=0.01673(-0.1213,0.1547)$

$\mathrm{p} 4=-0.003892(-0.2779,0.2701)$

The fitting curve is shown in Figure 6.

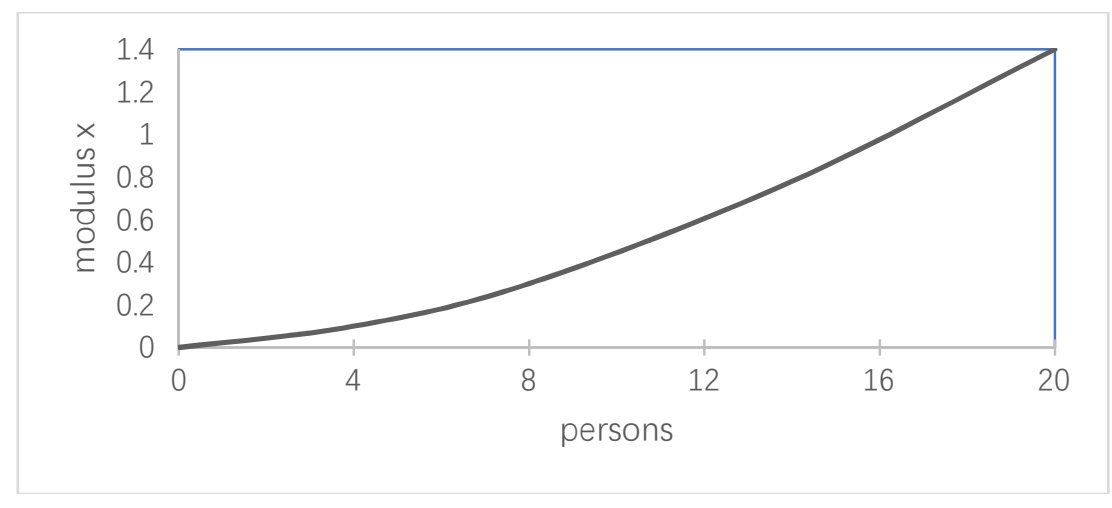

FIGURE 6. Fitting Curve

\section{SYSTEM TESTING}

The WeChat public number shows the indoor crowd density, as shown in Figure 7. 


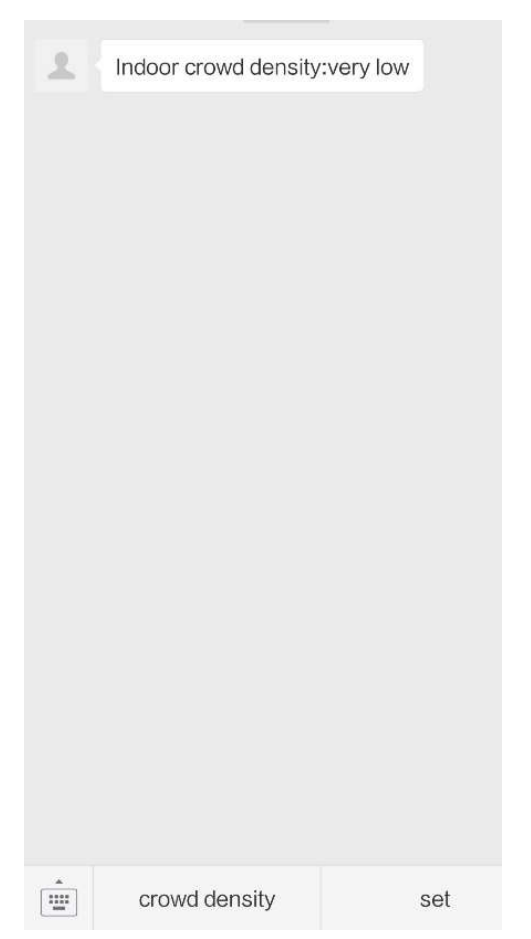

FIGURE 7. Wechat Public Account Screenshort

\section{CONCLUSION}

The article systematically collects and analyzes indoor temperature and humidity data and can effectively estimate the indoor population density. The system combines the WeChat public platform, which simplifies the development difficulty, reduces the cost [6], and facilitates the user's crowd density monitoring anytime and anywhere.

\section{REFERENCES}

1. Z.F.Dong.Design and Realization of Pet Feeding Remote Control System Based on Wechat Platform(Experiment Science and Technology,2017).

2. D.Zhang and H.W.Ding,"Research and Implementation of an Automatic Population Density Statistics System,"M.S. University of Electronic Science and Technology of China,2012

3. X.B.Zhao,Crow Density Monitoring System within Enclosed Spaces Based on Temperature and Humidity Sensor(Journal of Jilin University.,2016),pp. 237-243.

4. J.J.Wang,'The Research and Implementation of Edible Fungus Cultivation Environmental Monitoring and Technical Service System Based on Wechat Platform,"M.S. Shanghai Ocean University,2016.

5. T.Yan,'Design and Study on Application Technology of Air Quality Monitoring System Based on Internet of Tings,"M.S.Shangdong University,2016.

6. F. Shan and X.H.Tan,An Empirical Research on Mobile Micro-Learning Based on WeChat Public Platform(Open Education Research,2015),pp.97-104 